Research Article

\title{
Numerical Analysis on Influence of Punch Speed on Fluid Pressure in Hydro Forming Process
}

\author{
R.Uday $\operatorname{Kumar}^{\dot{A}}$, P.Ravinder Reddy ${ }^{\dot{B}}$ and A.V.SitaRamaraju $\dot{\mathrm{C}}$ \\ ${ }^{\AA}$ Dept.of Mechanical Engineering, Mahatma Gandhi Institute of Technology, Gandipet, Hyderabad. 500075.Andhra Pradesh. India. \\ ${ }^{\dot{B}}$ Dept.of Mechanical Engineering, Chaitanya Bharathi Institute of Technology, Gandipet, Hyderabad. 500075. Andhra Pradesh. India. \\ ${ }^{\mathrm{C}}$ Dept.of Mechanical Engg., JNTUH college of Engineering, Kukatpalli, Hyderabad. 500085. Andhra Pradesh. India.
}

Accepted 05 January 2014, Available online 01 February 2014, Special Issue-2, (February 2014)

\begin{abstract}
The hydroforming deep drawing process is one of the sheet metal forming process. The pressurized fluid is used as a medium in this process. Hydro forming technology provides an attractive alternative to conventional matched die forming, especially for cost - sensitive, lower volume production and for parts with irregular contours. The performance of deep drawing process can be enhanced by using the liquids. The process performance can be improved through improvement of parameters like draw ratio, thickness ratio, ratio of volume to surface area of product, no scratches developed on outer side of cup and formability index. In this process, the pressurized liquid is utilized for many purposes as the sheet metal blank is supported in entire forming process, elimination of fracture in deformation of cup and formation of wrinkles on the wall and edges of the cup are minimized. The liquid pressure effects on radial, hoop and drawing stresses of blanks in during the process. The liquid pressure is obtained from ANSYS Flotran CFD analysis software for using three oils such as castor oils, olive oil and heavy machine oil. The evaluation of oil pressures through change in the punch speed at constant punch radius. The pressure of oil is acting radially on surface of blank during the process. The radial pressure of oil is controlled by the blank holder pressure. As these two pressures are equal, the deformation of blank is uniform to get a required shape and also it prevents the blank failure during deformation. The pressure of oil depends on punch speed. The oil pressure increases with increase in the punch speed. The oil pressure is the dominant parameter for failure and success of forming of cups from the cylindrical blanks. This pressure of oil is used to evaluate the blank holding pressure. In this paper the numerical studies are carried on the effect of punch speed on oil pressure in hydroforming deep drawing process.
\end{abstract}

Keywords: CFD analysis, oil pressure, deep drawing process, CFD fluid model.

\section{Introduction}

The hydro-forming deep drawing process is a sheet metal forming process. It is widely used in industry for making seamless shells, cups and boxes of various shapes. In this process the pressurized oil is used as a medium. This pressurized oil is used to form component shapes. The process allows manufacturing lighter complex shapes more with increased strength at lower cost compared to more traditional techniques such as stamping, forging, casting or welding. The hydro formed components are used in the aerospace, automotive and other industries. In hydro forming deep drawing process pressurized oil is employed infront of the work piece. As the punch travels, the work piece begins to deform into a cylindrical cup. As per the literature survey available, the different types of fluid forming and pressurized oil as medium; are Hydroforming process(Tirosh, et al,1977), (Yossifon and Tirosh,1988), (Yossifon and Tirosh,1984), (Panknin and

*Corresponding author R.Uday Kumar is working as Associate Professor; P.Ravinder Reddy and , A.V.SitaRamaraju as Professor

DOI: http://dx.doi.org/10.14741/ijcet/spl.2.2014.02
Mulhauser,1957), (Thiruvarudchelvan and Lewis,1999), hydro-mechanical deep drawing process (Yang, et al, 1995), (Zhang and Danckert,1998), (Larsen,1977), Aqua draw process(Chabert,1976), hydraulic counter pressure process (Amino,et,al,1990), (Nakamura and Kanagawa,1984), (Nakamura and Nakagawa,1986). In general, in these processes the blank is subjected to fluid pressure on its periphery to get high forming limits and also preventing the failure. So there is improvement of deep drawing process for making the cups with utilization of fluid pressure. These processes have some differences and some features are common. These principles are utilized for improvement in production of drawing cups with help of hydraulic pressure through conventional methods.

The contribution of hydraulic pressure to the deep drawing process is positively in several ways. The frictional resistance reduces in the flange due to lubrication of flange and dies radius. In the present work an attempt has been made to evaluate and influence of punch speed on oil pressure by varying of punch speed using three oils medium through numerical analysis.

9 | International Conference on Advances in Mechanical Sciences 2014 


\section{Hydro forming process}

The hydraulic pressure is to be applied on the periphery of the blank in radial direction for successful formation of cup. The hydro-forming deep drawing process is shown in fig.1. The liquid is placed in the die cavity and punch chamber, which are connected through bypass path in the die. The gap is provided between the blank holder and die surface for the liquid and blank movement.

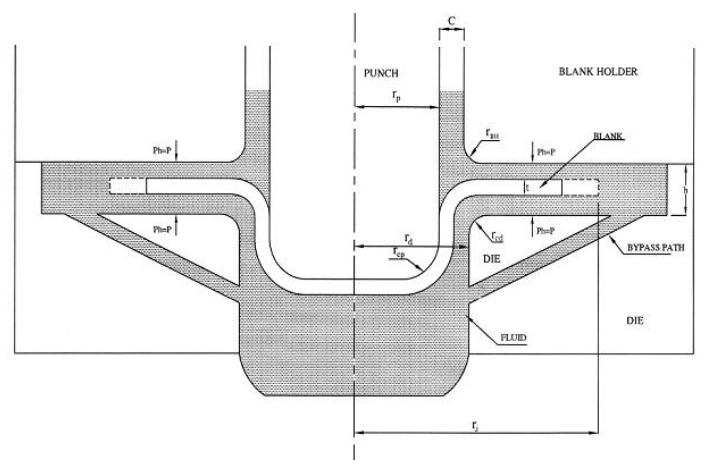

Fig.1 Hydro forming process - Deep drawing

The punch movement in the liquid chamber produces pressure in the liquid. This pressurized liquid is directed through the bypass path and acts radially on the blank periphery. The blank is supported by pressurized viscous liquid in between blank holder and die surface within the fluid region in the gap and a liquid film is formed on the upper and lower surfaces of blank which reduces frictional resistance. The wrinkling is reduced in the blank due to the support of high pressurized viscous liquid. The radial pressure of liquid which is produced due to punch movement within the liquid chamber is equal to blank holder pressure.This liquid pressure depends on the punch speed and various parameters of process. Evaluation of liquids pressure in this process by using ANSYS Flotran CFD numerical analysis software.

\section{Ansys Flotran CFD Analysis - Evaluation Of Liquid Pressure}

The study of variation of pressure of liquid with different punch speeds at constant punch radius using three liquids such as castor oil, olive oil and heavy machine oil through numerical analysis of Ansys - Flotran CFD. This pressure of liquid is to evaluate the blank holding pressure and analization of stresses in this process.

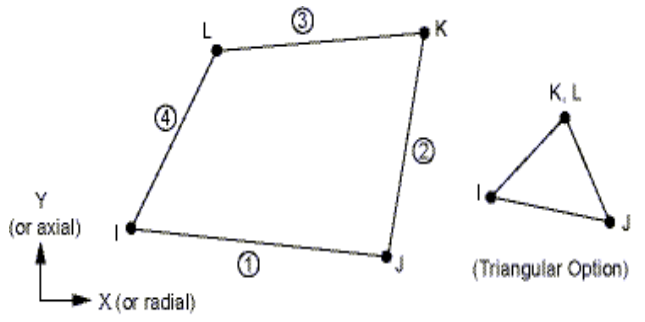

Fig.2 Geometry of FLUID 141Element

The element type is fluid 141 element from flotran CFD library is selected for meshing. The FLUID 141 element shown in fig.2. This figure shows FLUID 141 geometry, locations of node and coordinate system for this element. The element is defined by three nodes [triangle] or four nodes [quadrilateral] and by isotropic properties of material.

The fluid model is developed in Ansys preprocessing using geometric modeling approach. The radius of punch is $45 \mathrm{~mm}$, clearance between punch and die is $5 \mathrm{~mm}$ and radius of die opening is $50 \mathrm{~mm}$. The resulted geometry with 2D geometric options are shown in fig. 3

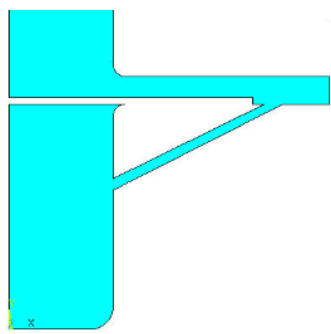

Fig.3 Geometric fluid model of the deep drawing process

Using adaptive mesh, a converged mesh is shown in fig. 4 The total number of elements and nodes in the model are 9846 and 11345.

Boundary and loading conditions :

$\mathrm{V}_{\mathrm{x}}=\mathrm{V}_{\mathrm{y}}=0$ on the boundary and Punch velocity, $\mathrm{V}_{\mathrm{y}}=10 \mathrm{~mm} / \mathrm{sec}$.

The fig. 5 shows the boundary and loading conditions of hydro forming process

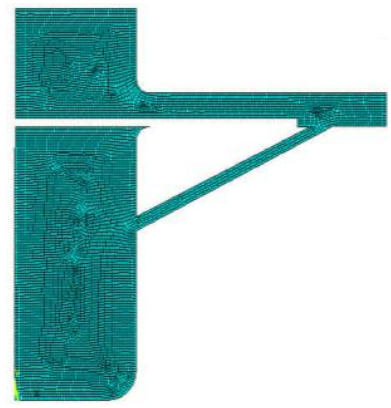

Fig.4 Flotran CFD model of the process

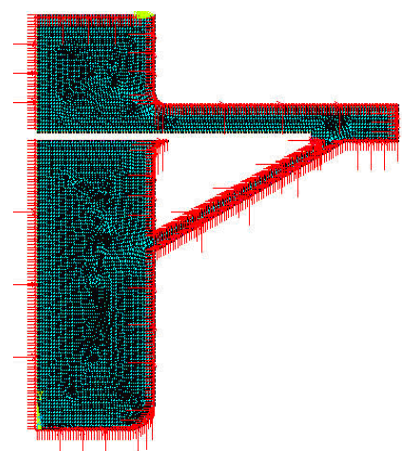

Fig.5 Boundary and loading conditions of the hydro forming process

10 | International Conference on Advances in Mechanical Sciences 2014 


\section{Results and Discussion}

The liquid pressure is evaluated with different punch speed at constant punch radius for three different oils such as castor oil, olive oil and heavy machine oil in hydroforming deep drawing process. The process parameters considered as punch speed $\mathrm{u}=10,20,30,40$ and $50 \mathrm{~mm} / \mathrm{sec}$, radius of punch $r_{p}=45 \mathrm{~mm}$ and radius of die opening $r_{d}=$ $50 \mathrm{~mm}$, height of the gap $\mathrm{h}=12 \mathrm{~mm}$. The viscosity of castor oil $\mu=0.985 \mathrm{~N}-\mathrm{sec} / \mathrm{m}^{2}$, viscosity of olive oil $\mu=$ $0.081 \mathrm{~N}-\mathrm{sec} / \mathrm{m}^{2}$ and viscosity of heavy machine oil $\mu=$ $0.453 \mathrm{~N}-\mathrm{sec} / \mathrm{m}^{2}$. Castor oil density $\rho=960 \mathrm{~kg} / \mathrm{m}^{3}$, heavy machine oil density $\rho=986 \mathrm{~kg} / \mathrm{m}^{3}$, olive oil density $\rho=$ $910 \mathrm{~kg} / \mathrm{m}^{3}$.The numerical analysis of ANSYS Flotran CFD analysis results are presented in fig. 6 .

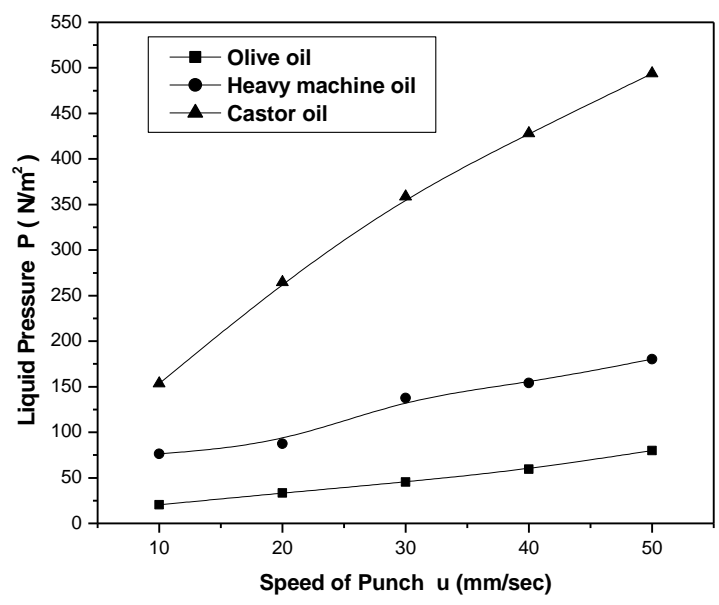

Fig.6 Effect of punch speed on liquid pressure at constant punch radius

From fig. 6 the liquid pressure increases with increase in the punch speed for all three liquids. The high pressures are obtained in castor oil medium and low pressures are obtained in olive oil medium. Also the pressure of oil depends on its viscosity. The range of liquids pressure for olive oil, heavy machine oil and castor oils are $20.5 \mathrm{~N} / \mathrm{m}^{2}$ $-79.8 \mathrm{~N} / \mathrm{m}^{2}, 76.4 \mathrm{~N} / \mathrm{m}^{2}-180.3 \mathrm{~N} / \mathrm{m}^{2}$ and $153.6 \mathrm{~N} / \mathrm{m}^{2}$ $493.7 \mathrm{~N} / \mathrm{m}^{2}$ respectively. The oils pressure is maximum at $\mathrm{u}=50 \mathrm{~mm} / \mathrm{sec}$ for castor oil is $493.7 \mathrm{~N} / \mathrm{m}^{2}$, heavy machine oil is $180.3 \mathrm{~N} / \mathrm{m}^{2}$ and in olive oil which is $79.8 \mathrm{~N} / \mathrm{m}^{2}$. At u $=10 \mathrm{~mm} / \mathrm{sec}$, the least variation is observed for castor oil is $153.6 \mathrm{~N} / \mathrm{m}^{2}$, heavy machine oil is $76.4 \mathrm{~N} / \mathrm{m}^{2}$ and olive oil is $20.5 \mathrm{~N} / \mathrm{m}^{2}$.High liquid pressures are found for castor oil medium and least in olive oil medium and within these heavy machine oil is observed.

In hydro forming deep drawing process, the liquid pressure is the dominant parameter for failure and success of forming of cups from the cylindrical blanks. The undesirable wrinkles are formed in the flange due to an insufficient pressure of liquid and premature tearing produced in flange due to excess liquid pressure. So appropriate pressure of liquid is used for success in forming of cups in this process.

\section{Conclusions}

The following conclusions are drawn from the present work.

- The wrinkling is reduced in the blank due to the support of high Pressurized viscous liquid

- The oil pressure is controlled

- The blank holder pressure is evaluated

- Oils pressure has been increased with increase in the punch speed

- Oils pressure in the process depends on the geometry of process and process parameters

- Oil pressure has been increased with increase in the viscosity of oil.

- The order of oils pressures are obtained as $\mathrm{P}_{\text {olive oil }}<$ $\mathrm{P}_{\text {heavy machine oil }}<\mathrm{P}_{\text {castor oil. }}$ at a given punch speed

- In this process oil pressure and blank holding pressure being equal so to get a required shape from uniform deformation of blank and also prevented failures in deformation of cup

- The hydro forming deep drawing process features can be developed by fluid pressure for producing the metallic cups

- The effect of oils pressure on radial, hoop and drawing stresses of blanks in during the process

\section{References}

T. Tirosh, S. Yosifon, R. Eshel, A.A. Betzer,(1977), Hyrdroforming process for uniform wall thickness products, Trans. ASME J. Eng. Ind. 99, pp.685-691.

S.Yossifon, J.Tirosh, (1988), On the permissible fluid-pressure path in hydroform deep drawing processes analysis of failures and experiments, Trans. ASME J. Eng. Ind.110, pp.146-152.

S.Yossifon, J. Tirosh, (1984), On suppression of plastic buckling in hydroforming process, Int. J. Mech. Sci. 26, pp. 389-402.

W. Panknin, W.Mulhauser, (1957),Principles of the hydroform process, Mitteilungen der forschungrges Blechvererbeitung 24, pp. 269- 277 .

S. Thiruvarudchelvan, W. Lewis, (1999), A note on hydroforming with constant fluid pressure, J. Mater. Process. Technol. 88 , pp. 51-56.

D.Y.Yang, J.B.Kim, D.W.Lee, (1995), Investigations into the manufacturing of very long cups by hydromechanical deep drawing and ironing with controlled radial pressure, Ann. CIRP 44, pp. 255-258.

S.H.Zhang, J.Danckert, (1998), Development of hydro-mechanical deep drawing, Journal of Mater. Process. Technol. 83 , pp.14-25

B. Larsen, (1977), Hydromechanical forming of sheet metal, Sheet Metal Ind. pp.162-166.

G. Chabert,( 1976), Hydro forming techniques in sheet metal industries, in Proceedings of the Fifth International Congress on Sheet Metal Work, International Council for Sheet Metal Development, pp. 18-34.

H. Amino, K. Nakamura, T. Nakagawa,(1990), Counter-pressure deep drawing and its application in the forming of automobile parts, J.Mater.process Technol. 23, pp. 243-265.

K. Nakamura, N. Kanagawa,(1984), Metal sheet forming process with hydraulic counter pressure, US Patent No. 4,472, 955 , pp 146-155

K. Nakamura, T. Nakagawa, (1986), Reverse deep drawing with hydraulic counter pressure using the peripheral pushing effect, Ann. CIRP 35 (1),pp.173-176. 